\title{
Some aspects of haemostasis after open-heart surgery
}

\author{
G. de GABRIELE \\ From the Regional Blood Transfusion Centre, Brentwood, Essex, and The London Hospital
}

SYNOPSIS In two groups of patients undergoing extracorporeal circulation with hypothermia, changes were found in the coagulation mechanism which were probably due to the dosage of polybrene administered.

The role of heparin and polybrene and the concept of activation of the coagulation mechanism in the production of bleeding after perfusion are discussed.

There are many factors concerned in the production of a bleeding diathesis following extracorporeal circulation with hypothermia. Two major factors are unneutralized heparin and the utilization of clotting factors and platelets induced by hypercoagulability of the blood during cardiac by-pass; fibrinolysis or the development of a circulating anticoagulant are occasional complications. Multiple minor coagulation defects may play their role in the potentiation of the post-operative bleeding. However, in many patients there appears to be no statistical correlation between coagulation studies and bleeding after perfusion; the bleeding as judged by thoracotomy drainage is excessive, but not clinically alarming, and stops spontaneously after 12 to 24 hours. In these cases capillary function may be deficient.

In a series of 12 patients undergoing open-heart surgery, the coagulation mechanism was investigated with special reference to the role of polybrene and heparin in the production of thrombocytopenia and coagulation defects.

It appears likely, as demonstrated by Perkins, Harkins, Gerbode, Rolfs, and Acra (1961) in dogs, that excess polybrene may produce a slight coagulation defect and also that heparin may produce a capillary defect.

\section{METHODS}

Twelve patients were investigated who had congenital or acquired heart disease and were undergoing open-heart surgery under superficial or profound hypothermia induced by the Drew technique.

All patients received $90 \mathrm{mg}$. of heparin for every square metre of surface area. In addition, $25 \mathrm{mg}$. heparin and $1 \mathrm{~g}$. calcium gluconate were added to each $420 \mathrm{ml}$. of donor blood which had been collected into $120 \mathrm{ml}$. of acidcitrate dextrose. Soon after collection, the blood was transported direct to the hospital so that it underwent Received for publication 30 January 1963 only one period of disturbance and refrigeration before use. The blood perfused during operation was either 24 hours old or a combination of 24 and 48 hours old. All the blood given in cases 6 and 11 was 48 hours old. Perfusion resulted in a $50 \%$ to $75 \%$ exchange of patient's blood by donors'. Any blood obtained by suction at the operation site was discarded.

In the first six cases (referred to as group $\mathbf{A}$ in the accompanying table), $2.0 \mathrm{mg}$. polybrene was given for each milligram of heparin used; in the remaining six cases (group B) $1.5 \mathrm{mg}$. polybrene was administered for each milligram of heparin.

Patients were investigated usually during the week preceding operation and each was found to have normal platelet levels, platelet adhesiveness, bleeding time (Duke), clotting time (Lee and White), prothrombin time, thromboplastin generation test, fibrinogen, calcium, urea, and electrolyte levels. Post-operative samples were taken two to four hours after polybrene had been administered.

Plasma platelet counts determined in the Coulter electronic cell counter were adjusted to whole blood levels in relation to the packed cell volume.

Platelet adhesiveness was measured by the method of Hellem (1960). Briefly, the method is as follows: citrated blood is filtered under standard conditions through a glass bead column. The difference in the number of platelets before and after filtration is expressed as a percentage of the total platelet count.

A euglobulin lysis time (von Kaulla and Schultz, 1958) was used as a measure of fibrinolysis.

Prothrombin time was determined by the Quick onestage method and partial thromboplastin time by the method of Rodman, Barrow, and Graham (1958).

A thrombin clotting time (Rothnie and Kinmonth, 1960) sample was taken 10 minutes after the infusion of polybrene was completed.

The total thoracotomy drainage in the first 24 hours was expressed in $\mathrm{ml} . / \mathrm{kg}$. of body weight.

\section{RESULTS}

Differences between the two groups were found in platelet levels, prothrombin time, and partial throm- 


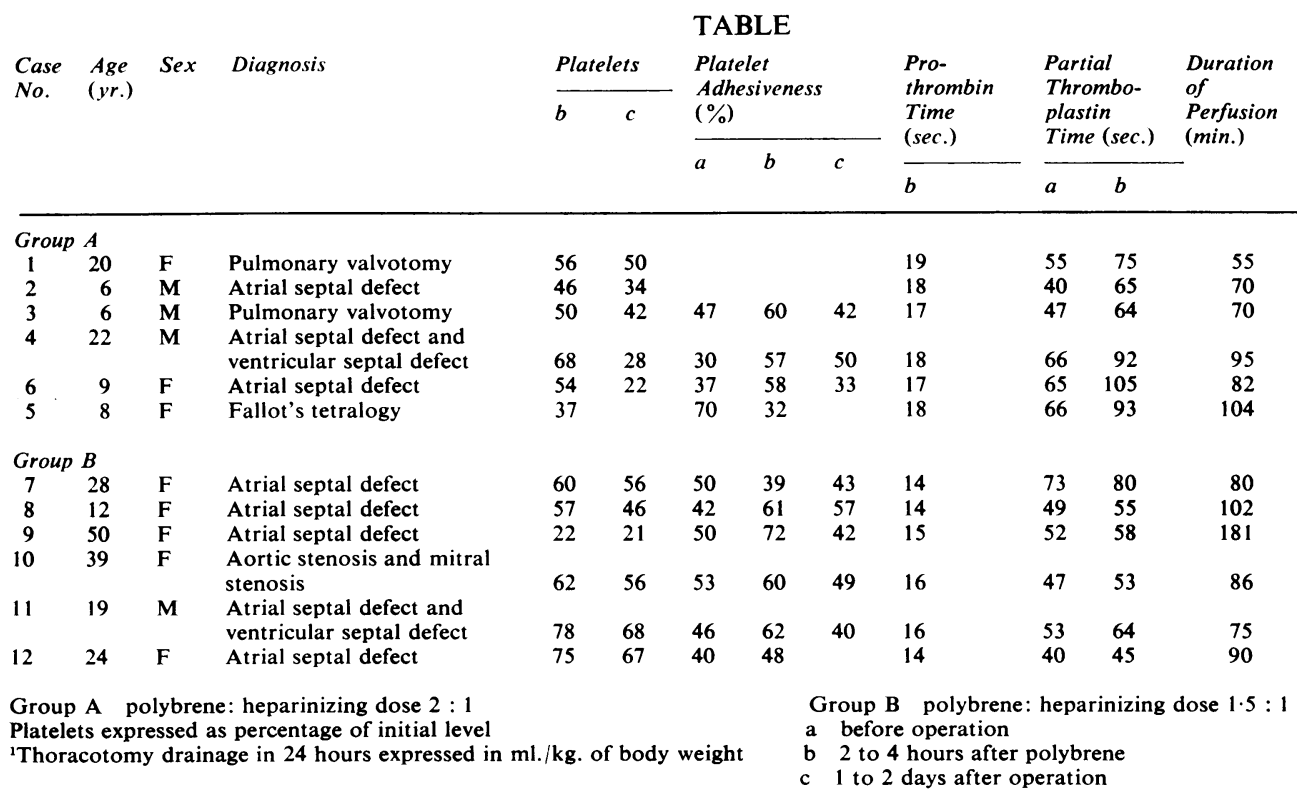

boplastin time. The principal results are shown in the accompanying table.

PLATELETS In all cases a decline in platelet levels was noted two to four hours after operation with a further decline by the next day. The changes were greater in group A. Usually a rise did not occur before the third post-operative day. A few hours after operation the average fall was to $52 \%$ of the initial level in group A and to $59 \%$ in group B. If one patient (case 9) in whom the duration of perfusion was markedly prolonged is excluded, the decline is to $66 \%$ in group B. By the next day the level had fallen to $33 \%$ in group A and to $52 \%$ in group B; excluding case 9 , the fall was to $59 \%$ in group B. These platelet changes did not appear to be influenced by the age of the blood, nor by the duration of perfusion ( 55 to 104 minutes) unless it was excessively prolonged181 minutes in case 9. In addition, there was no correlation between total platelet count and thoracotomy drainage.

PLATELET ADHESIVENESS In this series pre-operative values ranged from $30 \%$ to $70 \%$ (mean $46 \%$ ). During heparinization platelet adhesiveness was markedly reduced ( 0 to $5 \%$ ). After polybrene, adhesiveness increased on average from $46 \%$ to $59 \%$ with no difference between the two groups. This was not invariable, however, as in two cases it decreased; the decrease was to be expected in case 6 since the patient was polycythaemic pre-operatively and the P.C.V. was reduced by $25 \%$ immediately after oper- ation. A slight reduction below the pre-operative level was found on the first and second post-operative days. There was no correlation between adhesivenesso and thoracotomy drainage; and the same trend was noted in thoracotomy without extracorporealo circulation.

PROTHROMBIN TIME Pre-operative levels ranged fromō 12 to 14 seconds. After polybrene, prothrombin time was prolonged, an average of 18 seconds in group $\mathrm{A}$ and of 15 seconds in group B.

PARTIAL THROMBOPLASTIN TIME An average pro-: longation of 22 seconds in group A and 6 seconds in group B was found.

FIBRINOLYSIS This investigation was performed ino patients in whom thoracotomy drainage appeared moderate or excessive in the first few hours. Noo excessive fibrinolytic activity was present four hours after polybrene had been given.

THROMBIN TIME No evidence of unneutralized hep-N arin was found in either group and no antithrombin activity was detected in this series.

HAEMATOCRIT As a result of using acid-citrate dextrose blood, haematocrit fell on average by $10 \%$.

THORACOTOMY DRAINAGE Average drainage in 24त्ष hours was $19 \mathrm{ml} . / \mathrm{kg}$. (range $12-39 \mathrm{ml} / \mathrm{kg}$.) in group $\overrightarrow{\mathbb{D}}$ $\mathrm{A}$ and $17 \mathrm{ml} . / \mathrm{kg}$. (range $6-50 \mathrm{ml} . / \mathrm{kg}$.) in group $\mathrm{B} .2$ 
The excessive drainage in case 6 may be attributed to the development of pulmonary oedema, but there seems to be no contributory factor in case 12 . There appeared to be no correlation between the coagulation studies or duration of heparinization and thoracotomy drainage.

\section{DISCUSSION}

The activation of coagulation during perfusion, with consequent utilization of clotting factors and platelets, is consistent with the finding of normal or excessively complete prothrombin consumption immediately after perfusion with a decrease a few hours later(Brown and Smith, 1958). Gans, Siegal, Lillehei, and Krivit (1962) have demonstrated the development of hypercoagulability of either heparinized or acidcitrate dextrose blood (but not plasma) a few hours old circulated through a heart-lung machine alone; the breakdown of platelets and red cells was the factor responsible for the generation of a considerable quantity of thromboplastin. The hypercoagulability was kept in check by heparin or citrate, and was directly related to the duration of perfusion.

Comparable with the effect of perfusion is the simple transfusion of bank blood, the magnitude of the effect, after considering dilution, being related to the number of bottles transfused rather than to the age of the blood (Mustard, 1957; Krevans and Jackson, 1955; Stefanini, 1962).

Besides the concept of utilization of clotting factors induced by hypercoagulability, a contributory factor in the production of a bleeding diathesis may be the effect of heparin and polybrene on capillaries as well as on the coagulation mechanism.

Polybrene (hexadimethrine bromide) is a polymeric quaternary ammonium salt which acts like protamine and toluidine blue by neutralizing the electric charge of heparin. In vitro, polybrene in concentration comparable to that used clinically interferes with thromboplastic activity; the degree of inhibition varies indirectly with the platelet count (Shanberge, Regan, Talarico, and Busiek, 1961). Individual variation in the degree of inhibition occurs with polybrene as it does with heparin. Platelet clumping is produced by polybrene in vitro (personal observation). In dogs Perkins et al. (1961) found that 3 to $5 \mathrm{mg}$. polybrene $/ \mathrm{kg}$. of body weight produced a transient lengthening of the whole blood clotting time and reduction of platelet levels. After one hour, factors V and VIII are still reduced and prothrombin consumption and cephalin time are still abnormal. Kimura et al. (1959) has shown that larger doses produce prolonged reduction of platelet levels and disruption of mast cells with liberation of hista- mine, serotonin, heparin, and hyaluronic acid. Renal damage is a further complication.

Heparin similarly produces a transient reduction in platelet levels, probably due to sequestration. Large doses of heparin in rats, in which the thoracic duct had been cannulated, after a latent period of a few hours, produced an increased number of red cells in the lymph (Yoshimura and Djerassi, 1962). This effect persisted after coagulation and platelet levels had returned to normal and was not decreased by the administration of protamine. This effect was probably due to a direct interaction of heparin with the endothelial lining (Engelberg, 1962). It is possible that polybrene would have a similar effect.

Although the present study is small for statistical analysis, the results are compatible with the view that excess polybrene may produce a slight coagulation defect and that heparin may produce a capillary defect. There was a slight reduction in activity of the prothrombin complexes as judged by the one-stage prothrombin time, prolonged cephalin time, and reduced platelet levels. These changes were greater in the patients receiving the larger polybrene dosage. The laboratory evidence of a slight coagulation defect was not associated with a haemorrhagic diathesis as assessed by thoracotomy drainage. The drainage in both groups A and B was similar and caused no particular anxiety.

This mild and transient coagulation defect appears to be of little clinical significance. While it is probably important to neutralize all traces of heparin, it is wise not to exceed the dose of polybrene unless there is evidence of unneutralized heparin. The use of the thrombin clotting time test overestimates the requirements of polybrene since platelet-poor plasma is used and platelets have an anti-heparin activity. Also the anticoagulant activity of polybrene is increased in thrombocytopenic blood.

Many published cases show lack of correlation between coagulation studies and bleeding after perfusion, but the possible role of polybrene as a contributory factor is overlooked; also, heparin and polybrene should be considered, together with anoxia, acidosis, blood sludging, hypothermia, and poor tissue perfusion, as causes of capillary damage resulting in post-operative bleeding.

\section{ADDENDUM}

Since this paper was submitted for publication, polybrene has been discontinued because of the renal toxic effect and difficulty in providing a preparation of standard average molecular weight. Moreover, Stern and Rinker (1963) have found abnormal thrombus formation in vitro with the Chandler thrombogenerator in samples obtained 
30 to 60 minutes after polybrene had been given in open heart cases at operation; similar abnormal thrombi were obtained by adding polybrene alone to normal blood.

I wish to thank Dr. W. J. Jenkins, Director of the Regional Blood Transfusion Centre, for his very helpful criticism, and also Mr. C. Vernon Thompson and Mr. G. Flavell for permission to study patients under their care.

\section{REFERENCES}

Brown, I. W. and Smith, W. W. (1958). Ann. intern. Med., 49, 1035. Engelberg, H. (1962). Heparin. Thomas, Springfield, Illinois.
Gans, H., Siegal, D. L., Lillehei, C. W., and Krivit, W. (1962). Ann. Surg., 156, 19. Hellem, A. J. (1960). Scand. J. clin. Lab. Invest., 12, suppl., 51.
Kimura, E. T. et al. (1959). Toxicol. appl. Pharmacol., 1, 185 and $560 . \overrightarrow{\vec{H}^{\prime}}$ Krevans, J. R., andi Jackson D. P. (1955). J. Amer. med. Ass.. 159, 171 .

Mustard, J. F. (1957). Acta haemat. (Basel), 18, 80.

Perkins, H. A., Harkins, G.. Gerbode. F., Rolfs, M. R., and Acra, D. J. (1961). J. clin. Invest., 40,1421.

Rodman. N. F. Barrow, E. M., and Graham, J. B. (1958). Amer. J. clin. Path., 29, 525.

Rothnie, N. G., and Kinmonth, J. B. (1960). Brit. med. J., 1, 73.

Shanberge, J. N., Regan, E. E., Talarico, L., and Busiek, B. (1961). J. Lab. clin. Med., 58, 23.

Stefanini, M. (1962). Amer. J. med. Sci., 244, 298.

Stern, W. R., and Rinker, G. (1963). Fed Proc., 22, 250.

von Kaulla, K. N., and Schultz, R. L. (1958). Amer. J. clin. Path., 29, 104.

Yoshimura, H., and Djerassi, I. (1962). Blood, 20, 602. 